\title{
LA GLORIA DE DON RAMIRO: la trayectoria del héroe
}

\author{
Leonilda Ambrozio \\ Universidade Federal do Paraná
}

\section{RESUMEN}

Este análisis pretende estudiar la trayectoria del héroe que revela la propia condición humana, es decir, la lucha del hombre, oprimido por la dialéctica SER y NO SER.

La Gloria de Don Ramiro", la obra principal de Enrique Larreta (Argentina; 1873-1962), publicada en 1908, catalogada como "novela histórica", es una de las más importantes del género escrita en lengua española. En la opinión de Ángel J. Batistessa es "la novela histórica mejor lograda en nuestro idioma". Y más adelante vuelve a afirmar: "Según mi entender, su novela es la obra en prosa que en América se ha acercado más a la perfección literaria. Es la labor de un escritor, de un artista de conciencia y de la voluntad"2.

La novela se sitúa en el límite del final del romanticismo (por su "clima" a lo Walter Scott) con el inicio de Modernismo hispanoamericano por su preocupación con la forma, por su estilo y su lenguaje.

Como muy bien subrayó Amado Alonso, La Gloria de Don Ramiro es una novela histórica hecha según el molde modernista, lo que no deja de ser un contraste, es decir, por su ambiente, personajes y sucesos se configura como novela española; por su estilo, es una novela de la nueva corriente americana que, impregnada de influencia barroca, buscaba principalmente en lo exótico, material para su estética ${ }^{3}$.

El haber elegido España como escenario no es sino una manera de situar la obra en un ambiente contrastante. De um lado, el misterio, la austeridad, y santidad que trasciende de

1 IARRetA, Enrlque. La gloria de Don Ramiro; una vida en tiempos de Felipe Ir. Madrid, Espasa-Cripe, 1967. 258 p.

2 BATISTESSA. A.J. Goce $\mathbf{y}$ desengaño del mundo. Bolotín de la Academia Argentina de Letras (148/150): 272, 293, 1973.

3 ALONSO, Amado. Ensayo sobre la novela histórica; el modernismo en La Gloria de Don Ramiro. Buenos Alres, Universidad de Buenos Alres, Instituto de Pllosofla, 1942. p.151. 
las murallas de Ávila. Del otro, a plasticidad en las descriptiones del interior lujoso del periodo áureo de la historia española, pues según el subtitulo se trata de "Una vida en tiempos de Felipe II". Sin embargo, al elegir la época de Felipe II en lugar de la de Carlos $\mathrm{V}$, el autor asume la posición manriqueña de "todo pasa", porque ese período de la historia española es el de la predecadencia.

Antes de la génesis de la obra, Larreta ya manifestaba "el ambicioso designio de expresar en un solo libro el apasionante claroscuro del alma épica y monacal de España"4.

Larreta no sólo logró captar lo deseado, sino también llegó a contrastar "lo adusto y manriqueño" de la grandeza pasada con el ambiente cálido y sensual de la España musulmana.

Atilio Dell'Oro Maini dice lo seguiente sobre la cataloga. ción de La Gloria de Don Ramiro:

Ella pertenece al género histórico, es cierto; pero no se propone reconstruir un pasado, representar con cierta vivacidad, colorido y emoción, la historia de una época para ofrecer al lector, bajo los encantos de la fantasia, el espíritu de un pueblo o una colección de tipos de vida ya fenecidos, sin otro valor que el de pertenecer a un tiempo, o a una región más o menos olvidados; tampoco aspira a reproducir el cuadro de determinados sucesos de la historia o la vida de algunos de sus protagonistas, enriqueciéndolos con los prestigios del arte para darlos a conocer con la ilusión de una realidad más patética o cautivadora. Larreta alumbra, en el fondo auténtico de la historia de España, sintetizada y simbolizada en esta ciudad, a las criaturas de su fantasía, y éstas se mueven, dentro de su evocación, con un sentido pleno de verdadera unidad poética. ${ }^{5}$

\section{EL HEROE DON RAMIRO}

Don Ramiro forcejeaba en el mundo de contrastes: es noble y bastardo; fue educado en un ambiente español castizo pero se siente fuertemente atraido por el mundo de los moros que viven en los alrededores de Ávila; es algunas veces religioso y otras veces, soldado; disfruta los placeres mundanos, y se recoge en oraciones y arrepentimiento. A tra-

4 BATISTESSA, $\mathbf{0 . 2 8 5}$.

5 DELl'oRo MAINI. Atilio. Homenaje a la memoria de Don Enrlque Larteta. Boletín de la Academia Argentina de Letras (117/118): 323, 1965. 
vés de antítesis $\mathrm{y}$ tensiones, el personaje afronta los problemas a modo de pruebas que le van purificando hasta alcanzar la ulltima gloria, la verdadera gloria.

\section{ORIGEN DEL HEROE}

Como en el caso del héroe, el origen de Don Ramiro está envuelto en misterio. Hay algo obscuro en su nascimiento. A primera vista se trata de un huérfano, pues hasta cierto punto de la narrativa no existe ninguna referencia a la figura paterna. Sabemos que en la mitología universal abundan las referencias a la orfandad y abandono del héroe. Pese a que tiene madre y abuelo, Ramiro no deja de ser un huérfano porque se siente como si lo fuese.

A Don Ramiro nunca le mencionan el nombre del padre y desconoce si está vivo o muerto. No sólo su nacimiento es un misterio, sino que toda su infancia roza lo sobrenatural; su casa estaba siempre cerrada y con candelabros encendidos; su madre se vestía siempre como una monja y estaba siempre triste y callada; las historias de fantasmas que le contaba su vieja esclava, el ambiente sombrio de la ciudad donde vive. Hasta su fisonomia tiene ese aire:

Todos miraban con respetuosa ternura al párvulo triste y hermoso, que no habia cumplido aún doce años y parecia llevar en la frente el surco de misterioso pesar. (p.9)

Pese a la obscuridad de su nacimiento, el héroe trágico conserva el orgullo propio de la nobleza, nero la tendencia de la tragedia es aislar a la familia señalada de la sociedad. En el caso de Don Ramiro se da el aislamiento en dos planos: uno en relación a la sociedad, y otro entre los diferentes miembros de la familia que actúan como "islas":

Encerrado desde el amanecer hasta la noche en la libreria del palacio. don fñigo deiaba deslizar las horas muertas, meditando o leyendo. (p.17)

Guiomar y don fñigo se veían tan sólo a las horas de la comida y de la cena. (p. 20)

El abuelo no le hablaba jamás. (p.23)

Aparte del aislamiento, normalmente el héroe se ve envuelto en los conflictos de amor y honor. En La Gloria de Don Ramiro, se observa dicho conflicto ya en el origen del 
protagonista, pues $D$. Ramiro es el fruto del amor entre una mulher de familia ilustre y un moro, raza rechazada en la España cristiana. A su vez, Ramiro conoce y desea a la mora Aixa, pero rehuye el ambiente morisco por ser un representante de la ideologia cristiana. Por un lado, el personaje dice NO a los placeres mundanos para conservar la integridad de su ser; por otro, dice SI, traicionando su ascendencia noble, demostrando debilidad, matándose desde el punto de vista de su cultura, pero respondiendo a las necesidades vitales de su ser. Se debate entre las dos ansias, pero, por tratarse de un héroe, que es un "ser proyectado para la muerte", de la cual renace para la vida de la gloria, la narrativa se orientará hacia esa dirección.

\section{JUVENTUD DEL HEROE}

El héroe siempre presenta características humanas y sobrenaturales pues es el resultado de la unión entre un dios o diosa y un ser humano. En Don Ramiro, la ausencia de ese origen divino se sustituye por la "presencia" de Dios:

A los diez años de edad Ramiro parecía tocado de Dios. Su madre le veía internarse, como un predestinado, en la aspereza y el recogimiento (p.24).

Se puede decir que la juventud de Don Ramiro está marcada por innumerables pruebas que servirán para caracterizarlo como héroe. Como elementos que influyeron en su iniciación mencionamos en primer lugar las narraciones que le contaba Medrano, narraciones de libros de caballería o de sus aventuras como soldado:

Describía el desorden y la fuga de las naves cristianas al presentarse de improviso a la armada turquesca (p.13)

! Contaba entonces los horrores del asedio, las enfermedades desconocidas. las heridas monstruosas, el hambre, la sed! (p.13)

Otro elemento que contribuye a la formación del hombre Don Ramiro es el ambiente abulense cuyas murallas le hablaban de un pasado de lucha contra los moros:

Asi fue conociendo Ramiro la ciudad con sus arrabales y contornos. Era una revelación incesante para sus ojos hastiados del cuadro monótono del 
caserón. El afán diverso de la vida invadió bruscamente stu espiritu. Además, las fieras murallas le hablaron un lenguaje legendario y heroico, y los templos, con sus graves sepulcros, le dijeron las glorias del hombre y el orgullo de los linajes. (p.24)

La lucha con un perro rabioso en la niñez (p.36) ya nos da una muestra de su valor.

En la iniciación del héroe la figura del padre es reemplazada por la de un guía o preceptor. En La Gloria de Don Ramiro tenemos a Medrano que le inicia en el manejo de las armas, y a los preceptores que le inician en el campo de las letras y filosofía. A Medrano "Ramiro le escuchaba experimentando un singular deslumbramiento, y, al empuñar él mismo la espada, parecíale que el corazón le crecía dentro del pecho" (p.13).

El conflicto que notamos en Ramiro, esa alma atormentada que busca la gloria al mismo tiempo que lucha por un ideal, se debe principalmente a las influencias del primer preceptor. Aparte de su inclinación natural por la vida heroica por haberse enterado de la gloria de sus antepasados, por haber oído las historias y lecciones de Medrano, y por haber leído libros de caballería (p.34), se le imponen otros valores, los espirituales. De ahí proviene el conflicto en que se debate Don Ramiro durante toda su vida. Carece de fuerza de voluntad para optar por uno de los dos mundos. La lección del preceptor era la siguiente:

Buscaba siempre inculcarle el desprecio del mundo, y poseía para ello, como pocos, la elocuencia del ascetismo. Cuando hablaba de las glorias terrenas y de nuestro breve paso mundanal, su discurso, lleno de monástica ironía, se instilaba en el ser, cual frígido narcótico, adormeciendo las ansias, (p. 40-1)

El segundo preceptor le devuelve el entusiasmo por las armas al señalarle lo sórdido de la vida religiosa. En lugar de la lección de humildad, recibe la de ambición. Al leer las historias de héroes, Ramiro se siente como si fuera el mismísimo "héroe de la narración":

Dominado por la reverente admiración que profesaba a su maestro, y habiéndole entregado desde los primeros días todo su ánimo, Ramiro miró derechamente le senda que la señalaba aquella mano sacerdotal. Ya no dudó que en la carrera de las 
armas, siguiendo el ejemplo de sus antepasados, pudiera ser tan útil a Dios y a la Santa Iglesia como en el claustro o en el púlpito. Dióse entonces a descifrar los añejos pergaminos de su familia y leer la historia de los grandes capitanes de Roma y de España. El pronto, las representaciones de su propio porvenir se confundieron y conformaron a los grandes episodios antiguos. (p. 49-50)

La mayor cualidad de este segundo preceptor fue la de haberle devuelto la confianza en sí mismo, la principal caracteristica del verdadero héroe.

El resultado fue que llegó a creerse elegido de Dios para continuar la tradición de las glorias inolvidables. Suprimió de su campo mental lo mediano, lo prolijo, lo paciente. Todo lo que no era súbito y heroico le dejaba impasible, sintiendo em si mismo una confianza, una certidumbre absoluta de alcanzar de un golpe los honores más altos de los primeros paladines de la Fe Católica en la Tierra. (p.50)

\section{LA BUSCA}

La tercera etapa de la vida del héroe empieza cuando le imponen la realización de alguna hazaña heroica en que debe demostrar sus valores.A Ramiro le toca espiar. Debe penetrar en el mundo de los moros y hacer una investigación. El orgullo de su misión estaba en buscar a unos conspiradores moros, pero, en realidad, lo que buscaba era su propia gloria. En esta hazaña Ramiro pasa por una prueba decisiva, la tentación carnal, a la qual no resiste. Según Durand, "la chute se voit (...) symbolisée par la chair doit la chair que l'on mange, soit la chair sexuelle, le grand

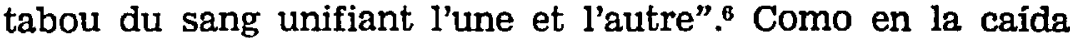
del héroe mítico, Ramiro "baja" al centro de la tentación, es decir, a la alcoba de Aixa. No sólo nos percatamos de la semejanza con Jesús, que descendió a los infiernos y con Adán que sufrió la tentación de la carne, sino también sentimos la propia ideología de la Iglesia Católica que prohibe dichos placeres. Vemos aún al contraste de la belleza y la sensualidad de la España musulmana con el terror del pecado y del castigo divino divulgados por la España cristiana, en que se debaten las tensiones entre el SER y el NO-SER.

6 DURAND. G. Les structures anthropologiques de limaginaire. Paris, Bordas, 1973. p.170. 


\section{LA CAIDA}

El héroe abandonó el orden cultural (cristiano), regido por leyes estrictas de moral y entra en el orden natural (musulmano), que considera los placeres como algo inherente a la vida:

Por fin, olvidando por completo la investigación que tenia que realizar, destemplado por el amor, relajado por la molicie, Ramiro fue aceptando, insensiblemente, todos los refinamientos que constituían la vida habitual de su manceba (p.79)

Ramiro no tiene fuerzas para vencer a las apelaciones de la carne, por lo que, según la ideología cristiana, es un ser corrompido por el pecado de la lujuria:

Entonces aparecieron, en su intacta firmeza, los fuertes pechos bruñidos y casi dorados como copas de ámbar; y el mancebo sintió correr por toda su carne la tentación de aquella cintura cogida y de las abultadas caderas, irisadas por la humedad y la penumbra. (p.76)

Por no tener fuerzas suficientes para sobreponerse a la tentación, sería encuadrado en la categoria de "héroe Iunar", de acuerdo con la terminología durandiana, puesto que la "desobediencia del héroe solar" está cargada de rebeldía. Pero Ramiro es un héroe débil:

Se mi constelación deciase ahora a sí mismo no anuncia qué he de morir de esta guisa todos los ardides seran varios. Si, por el contrario, este ha de ser mi acabar, a qué resistirme? (p.74).

Para Durand todo descenso es lento y está relacionado con la intimidad protectora. Ramiro pasa en primer lugar por un pasillo subterráneo frío $\mathrm{y}$, en seguida, se encuentra en un ambiente donde el calor, el perfume, la penumbra crean una atmósfera sensual y acogedora.

Dominan las imágenes sexuales en esta narración a partir de la penetración en ese pasillo:

Ramiro, al descender, hallóse en una cuadra ruinosa y obscura. La anciana vendóle los ojos con negra tira de lienzo $\mathrm{y}$, tomándole de la mano, comenzó a conducirle, sin duda, a lo largo de un cor- 
redor subterráneo, a juzgar por el frio que sentia en las espaidas $y$ el olor terroso del ambiente (p.74).

Y más adelante: "Bajaron algunos peldaños y la anciana silbó junto a él". (p.74). En este descenso, el héroe desobedece el orden de su cultura. Como el acto de amor es a la vez muerte y búsqueda del Absoluto, Ramiro "muere" en esta "caida" para renacer purificado, aunque luche contra su propia consciencia:

En ese instante, por encima de sus sentidos ávidos, Ramiro escuchó en su conciencia un grito de indignación ante aquella práctica lasciva de los baños y aquel culto libidinoso de la propia carne (p.76).

La ideologia cristiana, mejor dicho, la católica, de su formación, el sacrificio de las penitencias de los santos resuenan en su mente:

La sublime castidad, el ascético abandono, el desprecio y la mortificación del harapo corrupto de nuestro cuerpo, la santa fetidez de los religiosos, los admirables anacoretas dejándose podrir las ropas sobre la piel, como un anticipo de la sepultura: San Hospicio, comido por los piojos; San Macario, sumergido en el cieno; Santa María Egipcíaca, resecada por el sol como un cuero; Santa Pelagia, habitando entre sus propios excrementos; Santa Isabel, bebiendo el agua de lavar tiñosos; en fin, la sublime aspiración abriendo su corola de pureza sobre el estercolero corporal; y luego de la penitencia, la disciplina, el cilicio, todo pasó por su mente como a la luz de un relámpago (p.77).

La caída del héroe no sólo se realiza en el nivel religioso, sino también en el plano moral, puesto que al abandonar la investigación, viola la ley de la sociedad en que vive. A esa muerte moral y religiosa sucede la casi-muerte física del héroe. Al encontrarse gravemente herido, un moro desconocido le salva.

La caída típica del héroe trágico se da debido a la hybris, un ánimo apasionado que actúa como "precipitador normal da catástrofe". A Don Ramiro le falta ese espíritu de lucha:

7 FRYE. N. Anatomia da critica. Säo Paulo, Cultrix, 1973. p.207. 
Pero la severa visión no pudo persistir. Los sentidos tiraban de las traillas. El turbión de la virilidad apagaba las luces interiores: !Alli estaba ante él una mujer hermosa y desnuda, a dos pasos de su boca, de su juventud!

Dominado por aquella tentación, vibrando con ella, cual un junco en el torrente, Ramiro no vio que la criada, describiendo un rodeo, se dirigía a tomar las babuchas en el hueco del muro (p.77).

La cabellera, simbolo del destino humano, teje, trama, envuelve. La mora Aixa hila el destino del héroe con sus cabellos que se configuran más que nada como serpientes a los ojos de Ramiro:

La quietud dejaba flotar o embeberse la suelta cabellera esponjosa y enorme que hacía pensar en los copos destinados a tejer todo un manto. Algunos mechones que conservaban la oleosidad de los unguientos pendían de uno de los bordes. Era también su guedeja o las serpientes fascinadoras de algún extraño sortilegio? (p.75).

Podemos ignorar aqui la imagem sexual clásica, según la cual la serpiente es un símbolo fálico "parce que sa forme oblongue et son cheminement suggérent la virilité du pénis"8, puesto que en el caso de La gloria de Don Ramiro está más bien relacionada con la regeneración, con el retorno. ${ }^{9}$ Siguiendo todavia la teoria durandiana, la serpiente "animal du mystère souterrain ( ...), il assume une mission et devient le symbole de l'instant difficile d'une révélation ou d'un mystére: le mystére de la mort vaincue par la promesse de recommencement". ${ }^{10}$

Observamos que no sólo la cabellera de Aixa, sino todo su cuerpo, al bailar, nos remite a la figura de la serpiente: "Su cuerpo comenzó a quebrarse hacia uno y otro lado con lenta contorsión" ( $p .82)$. Y más adelante:

"Aixa golpeó entonces a las losas con los pies, haciendo repiquetear el oro y el marfil que recargaban sus tobillos $\mathrm{y}$, con los ojos abstraídos, giró sobre si misma esparciendo perfumada frescura, cual húmeda flor sacudida de pronto" (p.82-3). 
Es precisamente en ese momento, en la presencia de Aixa, cuando aparece el mismo moro que le habia salvado la vida y que casualmente es el amigo de la otra. Poco a poco se va configurando la revelación, la aclaración del misterio de su padre. Sin embargo el héroe tendrá que pasar por más etapas antes de estar preparado para esta revelación. Por ejemplo, recibirá un castigo en su propia carne. La carne que lo hizo caer, será el medio de su mortificación. Lo que era la fuente de placeres, se transforma en sufrimiento, en dolor, en debilitación, en malos olores: "La carne toda se sentía fenecer. Era una sensación glacial, tenebrosa' (p.101); "La gangrena difundia su fetidez por las estancias vecinas" (p.101). Es el período en que repasa su vida; pero, al ser un héroe que se debate entre lo espiritual y lo humano, se deja llevar por la fiebre de la ambición:

Su ambición, segada por el sufrimiento, rebrotaba ahora con savia más fuerte. Consideró que Dios no le habia llamado porque le reservaba algún servicio insigne en la tierra. Acababa de pasar por la primera prueba de las vidas predestinadas. Recordó la biografía de los heróes. El comienzo de la fortuna orilló casi siempre los despeñaderos. La hoja mejor batida era aquella que había estado más cerca de partirse en la bigornia. Nueva confianza en su destino erguía ahora su hercúlea voluntad, y sentiase como ebrio de ilusión, llegando a decirse a si mismo las frases admirativas que su sola presencia provocaría muy pronto por doquier (p.102).

\section{EL RECORRIDO}

A lo largo del recorrido existencial, todo héroe hace frente a varios sucesos y circunstancias que le sirven de etapas de purificación o de pruebas por las cuales tiene que pasar.

En la vida de Don Ramiro la pérdida de fortuna de su familia es una de esas pruebas. Este hecho hiere su orgullo de "raza noble", y una vez más el destino le impide la ascensión social.

En segundo lugar, tenemos el conflicto trágico cuyo centro es la figura femenina de Beatriz. Al contrario de la comedia en que las condiciones favorecen al Amor, en la tragedia el amor no se realiza y su final es trágico. Ramiro ama a Beatriz, pero al ser rechazado por ser hijo de moro, planea una venganza contra Gonzalo que también disputaba 
el amor de la muchacha. Lo mata en duelo, y en seguida va disfrazado al encuentro de Beatriz, pero al sentir que los besos apasionados que recibia, pertenecían al otro, ciego de despecho, mata a Beatriz, transgridiendo la ley una vez más.

Ramiro recibió de lleno el aletazo de la demencia. Todo su ser rechinó cual la hoja ígnea que el espadero sumerge de golpe en el agua. Sentia que su mente giraba en una vorágine de negrura, y escuchaba dentro de su cerebro el ladrido de las potencias tenebrosas de la venganza; no viendo sino una sola idea, una sola necesidad, una sola justicia: El exterminio, la muerte! (p.207)

Ramiro se impone el exilio y huye de Ávila, la ciudad que siempre le cobijó dentro de sus murallas, y se dirige a Toledo, la "ciudad expiatoria". Sin dinero, se emplea como paje de un conde, y como tal, es obligado a convivir con los demás miembros del servicio.

Así como la tragedia viene a ser arquetípicamente la imitación de un sacrificio, en La Gloria de Don Ramiro dicho sacrificio está representado por la misma visión del Infierno, de las horrorosas escenas de muerte en las hogueras de la Inquisición. Simboliza el sacrificio por la cantidad de inocentes que fueron condenados. En esta narrativa el sacrificado no es el héroe, sino Aixa, la mora con quien pasó tantas horas de placeres. A lo largo de la narración, se espera que intente salvarla o que al menos demuestre piedad, pero esta esperanza del lector no se cumple, puesto que Ramiro actúa pasivamente como un mero expectador, con lo cual prueba que su aspiración heroica tiene un límite. Como ya vimos anteriormente, le falta la hybris del héroe tradicional. Una vez más, sentimos aquí la configuración del antihéroe de la narrativa vanguardista. Es el héroe alejándose de los dioses y acercándose a las debilidades humanas.

Asimismo, al contrario del verdadero héroe, que se conserva joven, Don Ramiro pierde su antiguo vigor. Ya no es el muchacho ávido de luchas y victorias:

Una apatía, una pereza invencible comenzó a postrar como un ensalmo sus miembros y su espíritu, hasta hacerle pasar la mayor parte del dia tendido en la cama del anacoreta, ocupado en contar los hoyuelos de la roca o las gotas de agua que cafan de las vertientes. Las lagartijas, las cucarachas, los ratones y muchos insectos que le eran desconocidos acabaron por trepar sobre su cuerpo, y él, 
en vez de espantarlos, mantenia completa inmovilidad, a fin de observar de cerca todos sus movimientos. (p.247)

La espada que fue usada tantas veces para matar, será un instrumento de rescate del héroe con su pasado, una vez que, al intentar matar a un anciano, sucede que por las tramas del Destino es su padre:

Entonces el anciano inclinó su cuerpo hacia delante $\mathrm{y}$ por toda respuesta escupió dos veces con bárbara osadía la santa imagen del Redentor. Ramiro exhaló um grito de espanto. Su cuerpo vacilaba combatido por dos impulsos adversos. Por fin, corriendo con impetu a la cuerva, cogió la espada y se vino derecho hacia el hombre, con la intención de darle muerte alli mismo. Pero al levantar la punta para hundirla en aquel pecho sacrílego, una voz recia y dominante, una voz que penetró en las entrañas le contuvo de golpe: - Ah! Ramiro, Ramiro, sólo falta agora que acuchilles al hombre que te engendró! ( $p .249$ ).

Hay cambio completo en su vida: ya no es el noble Ramiro, sino un hijo de moro:

Seria verdad? Seria, en efecto, hijo de moro? Ah! Más le valiera entonces romperse las venas y dejar que toda su sangre se derramase sobre el lodo de la ignorada caverna. (p.250).

Esta revelación es el inicio de una nueva etapa de su vida. La espada, como el agua o el fuego, aparece como el símbolo de la purificación. Por otra parte, las palabras acusadoras de su padre le hacen pensar en otra vida:

Soñaba con alguna región de las Indias, donde las plantas, las frutas, las aves, las estrellas, todo fuera nuevo para él y nada le recordase la tierra vieja y maligna en que habia nacido, aquella tierra en que todo era adversidad, maleficio, embrujamiento. Sólo así podría escapar a la maldición que le perseguía, quizá, desde el vientre de la madre. (p.250)

Segun Durand, la espada está relacionada con la búsqueda de un lugar santo, de otro microcosmo: es el símbolo 
de la conquista. Lo que pretende Ramiro es zarpar al Perú, cruzar el océano, conquistar nuevos mundos. La agresividad de la espada se convertiria asi en una fuerza benéfica, seria la "virilidad del Destino". De este modo, al levantar el arma contra su padre, el destino interviene favorablemente y su vida cambia de forma radical. Más que nada, al ser "verticalidad", se considera la espada como el símbolo de la trascendência.

\section{EL VIAJE}

Para alcanzar la verdadera gloria, $D$. Ramiro desprecia los valores de su cultura y sale a una tierra nueva en busca de otros. Al desnudarse y disfrazarse de aborígen, se libera de la cadena de una cultura secular, europea, y asume los valores de una cultura joven, "americana".

A lo largo de su recorricio (=Vida) el héroe pasa por varias etapas de aprendizaje que lo van purificando.

Por otro lado, perdida ya su antigua identidad, el resultado es el Caballero Trágico, el que "disfrazado de salvaje pasaba todos los dias más de cinco horas en las entrañas de la tierra" (4.257), trabajando en la mina "Hedionda" en sustitución de un indígena a quien estaba curando un terrible dolor en los huesos.

Despojado de sus bienes terrenales, su verdadeira gloria fue una oración por su alma salida de los labios de Rosa de Santa Maria: "Y ésta fue la gloria de Don Ramiro".

En general, el viaje cierra el ciclo del recorrido del héroe:

Le symbolisme du voyaje, particulièrement riche, se resume toute fois dans la quête de la verité, de la paix, de l'immortalité, dans la recherche et la découverte. ${ }^{11}$

Esta búsqueda no es sino la búsqueda de sí mismo. Para Mircea Eliade marca el pasaje de lo profano a lo sagrado.12 Por no haber logrado una vida de gloria en España, Ramiro decide partir para América en busca de sí mismo. El Nuevo Mundo representa una especie de lugar de purificación donde se encuentra a si y a Dios. América simboliza del mismo modo la pureza inicial, la réplica del Paraíso, pero el verdadero Paraíso, lo conquistó D. Ramiro con su último viaje: la muerte. Al morir, nació para la gloria y para otra vida, puesto que el héroe no muere, sino que renace por medio de la palabra.

11 Chevalier, J. \& GHERBRandt. A. Dictionnaito des symboles. Parls, Beghers, 1974. D.407.

12 ELIADE, Mircea. The myth of eternal return. New York. Harper and Row, 1959. p.18. 


\section{CONCLUSION}

Amado Alonso analizó al héroe Ramiro y nos hizo ver la dualidad conflictiva de su alma que forcejeaba entre la fantasia y el idealismo. Según el crítico, para Don Ramiro, hasta su ansia de santidad se reducia a que la gente lo celebrase. ${ }^{13}$

Em nuestro análisis notamos que Enrique Larreta, intencionadamente o no, creó un héroe moderno, lleno de conflictos, que no conlleva la hybris del héroe trágico. La ausencia de voluntad, reclamada por Amado Alonso, tal vez sea el prenuncio del antihéroe de la novela contemporánea. Si Larreta hubiese seguido todas las caracteristicas del héroe tradicional, La Gloria de Don Ramiro no pasaría de una buena novela histórica en prosa modernista. La inserción del héroe en el ambiente rico y colorido de la España del siglo XVII se debe principalmente a la preocupación estética del Modernismo hispanoamericano. El ambiente rico favorecía la riqueza del lenguaje. Además, la exótica España de los moros seria la prolongación del lejano Oriente, donde los modernistas solian buscar subsidios para las creaciones literárias.

La modernidad de la obra publicada em 1908 reside en la creación de un héroe cuyas caracteristicas se aproximan a las de un antihéroe.

Al proceder a una lectura más profunda, podemos observar que esas dos características se aglutinan en esta novela, y revelan la propia condición humana, es decir, la lucha del hombre, oprimido por la dialéctica del SER y NO SER en la búsqueda del Absoluto.

\section{RESUMO}

Esta anälise pretende estudar a trajetória do herói que revela a própria condiçāo humana, ou seja, a luta do homem, oprimido pela dialética SER ou NAO.SER.

\section{REFERENCIAS BIBLIOGRAFICAS}

1 ALONSO, Amado. Ensayo sobre la novela histórica; el modernismo en La Gloria de Don Ramiro. Buenos Aires, Universidad de Buenos Aires, Instituto de Filologia, 1942.

2 BATISTESSA, A.J. Goce y desengaño del mundo. Boletin de la Academia Argentina de Letras (149/150:271-311, 1973. 
AMbrozio, L. La glotia de Don Ramito

3 CHEVALIER, J. \& GHERBRANT, A. Dictionnaire des symboles. Paris, Seghers, 1974.

4 DELL'ORO MAINI, Atilio. Homenaje a la memoria de Don Enrique Larreta. Boletín de la Academia Argentina de Letras (117/118): 322-8, 1965.

5 DURAND, G. Les structures anthropologiques de l'imaginaire, Paris, Bordas, 1973.

6 ELIADE, Mircea. The myth of eternal return. New York, Harper and Row, 1959.

7 FRYE, N. Anatomia da critica. São Paulo, Cultrix, 1973.

8 LARRETA, Enrique. La gloria de Don Ramiro. Madrid, Espasa-Calpe, 1967. 